BMJ Open Sport \& Exercise Medicine

\title{
Efficacy of platelet-rich plasma injections for symptomatic tendinopathy: systematic review and meta-analysis of randomised injection- controlled trials
}

\author{
Larry E Miller, ${ }^{1}$ William R Parrish, ${ }^{2}$ Breana Roides, ${ }^{2}$ Samir Bhattacharyya ${ }^{2}$
}

To cite: Miller LE, Parrish WR, Roides B, et al. Efficacy of platelet-rich plasma injections for symptomatic tendinopathy: systematic review and metaanalysis of randomised injection-controlled trials BMJ Open Sport Exerc Med 2017;3: 000237 .

doi:10.1136/bmjsem-2017000237

Received 08 February 2017 Revised 28 May 2017 Accepted 25 August 2017
CrossMark

\footnotetext{
${ }^{1}$ Miller Scientific Consulting, Asheville, North Carolina, USA

${ }^{2}$ Department of Research and Development, DePuy Synthes Mitek Sports Medicine, Raynham, Massachusetts, USA
}

Correspondence to Dr Larry E Miller; larry@ millerscientific.com

\section{ABSTRACT}

Aim To determine the efficacy of platelet-rich plasma (PRP) injections for symptomatic tendinopathy.

Design Systematic review of randomised, injectioncontrolled trials with meta-analysis.

Data sources Systematic searches of MEDLINE and EMBASE, supplemented by manual searches.

Eligibility criteria for selecting studies

Randomised controlled trials with 3 months minimum follow-up that evaluated pain reduction with PRP versus control (saline, local anaesthetic, corticosteroid) injections in patients with symptomatic tendinopathy.

Results A total of 16 randomised controlled trials (18 groups) of PRP versus control were included. Median sample size was 35 patients, a study size that would require an effect size $\geq 1.0$ to achieve statistical significance. PRP was more efficacious than control in reducing tendinopathy pain, with an effect size of 0.47 $(95 \% \mathrm{Cl} 0.22$ to $0.72, \mathrm{p}<0.001)$, signifying a moderate treatment effect. Heterogeneity among studies was moderate $\left(I^{2}=67 \%, p<0.001\right)$. In subgroup analysis and meta-regression, studies with a higher proportion of female patients were associated with greater treatment benefits with PRP.

Conclusions Injection of PRP is more efficacious than control injections in patients with symptomatic tendinopathy.

\section{INTRODUCTION}

Tendinopathy is the most common musculoskeletal complaint in patients seeking medical care. ${ }^{1}$ The most common sites of presentation include the elbow, rotator cuff, Achilles tendon and patellar tendon. With early diagnosis and timely application of traditional non-surgical treatments such as activity modification, gentle static stretching, anti-inflammatory medications and/or eccentric loading, the prognosis is favourable in the acute stage. However, symptoms may persist in some patients despite exhausting these treatment options. Recalcitrant tendinopathy may manifest because, once damaged, the

\section{What is already known?}

Chronic tendinopathy presents a therapeutic challenge to clinicians and there is no consensus on preferred treatment regimens.

- While platelet-rich plasma (PRP) injections have shown generally positive results in tendinopathy, study designs and PRP preparation methods vary widely which complicates interpretation of efficacy.

\section{What are the new findings?}

Injection of PRP is more efficacious than control injections in patients with symptomatic tendinopathy.

- PRP injections for symptomatic tendinopathy may be more efficacious in women than men.

- The sample sizes of most PRP studies for symptomatic tendinopathy are too small to statistically detect clinically meaningful treatment effects.

biological and biomechanical properties of connective tissue are never completely restored. Healing times in chronic tendinopathies are prolonged as tendons are relatively hypovascular and local blood flow is only about one-third of that delivered to the muscles. ${ }^{2}$

Since the aetiology of chronic tendinopathy is controversial and likely multifactorial, numerous therapies with various mechanisms of action have been attempted although none have an ideal efficacy and safety profile. Therapies intended to reduce inflammation such as local cooling, non-steroidal anti-inflammatory drugs and corticosteroids are commonly prescribed, yet the premise for application of these modalities is misguided given the 


\section{Box 1 MEDLINE search strategy}

\section{DIAGNOSTIC SEARCH TERMS}

- Achilles

- Epicondyl*

- Gluteus

- Patellar

- Rotator cuff

- Tendinopathy

- Tennis elbow

\section{THERAPEUTIC TERMS}

- Autologous conditioned plasma

Platelet-rich plasma

PRP

\section{COMBINATION TERMS}

or $/ 1-7$

or/8-10

and $/ 11-12$

*Represents a wild card symbol used in a search query to represent end truncation.

absence of a measureable inflammatory response in or around the lesion in chronic tendinopathy. ${ }^{3}$ This may partially explain their limited efficacy in recalcitrant tendinopathy cases.

Tendinosis forms as an imbalance between the demands that are placed on a tendon and its ability to remodel. Recent developments in biological research have emphasised the importance of growth factors in the maintenance of normal tissue structure and repair of tissue lesions. ${ }^{4}$ Platelet-rich plasma (PRP) is a blood derivative with a platelet concentration greater than that of whole blood that is an emerging regenerative therapy for tissue injury and degeneration. Activated platelets release biologically active proteins that promote cellular recruitment, growth and morphogenesis. ${ }^{5}$ Soft tissue healing is thought to be stimulated via enhanced fibroblast migration and proliferation, upregulated vascularisation and increased collagen deposition. ${ }^{6}{ }^{7}$ These biological properties are appealing in the treatment of tendinopathy, which has poor intrinsic healing ability. Among the studies performed on PRP injection in the treatment of tendinopathy, study designs and PRP preparation methods have varied widely which complicates interpretation of PRP efficacy. The purpose of this systematic review and meta-analysis was to determine the efficacy of PRP injections for tendinopathy by evaluating randomised controlled trials of PRP injection versus control injection. A secondary purpose of this research was to explore sources of heterogeneity in treatment outcomes among studies.

\section{METHODS}

\section{Study selection}

The study was performed according to PRISMA (Preferred Reporting Items for Systematic Reviews and Meta-analyses). ${ }^{8}$ Two researchers independently searched MEDLINE and EMBASE for randomised controlled trials of PRP injection versus control injections (saline, local anaesthetic or corticosteroid) for treatment of tendinopathy using a combination of diagnostic and therapy-specific keywords and MeSH terms. The details of the MEDLINE search strategy are listed in box 1. The syntax for EMBASE was similar, but adapted as necessary. Additionally, reference lists of included papers and relevant meta-analyses were manually searched. No date or language restrictions were applied to the searches. The final search was performed on 30 November 2016. Main inclusion criteria included randomised controlled trial of PRP injection; control group treated with control injection (saline, local anaesthetic or corticosteroid); primary diagnosis of symptomatic tendinopathy; minimum follow-up period of 3 months; and extractable measures of pain at baseline and post-treatment. When multiple studies included overlapping series of patients, only the study with the largest sample size or longest follow-up duration was included. Study selection discrepancies between the two researchers were resolved by discussion.

\section{Data extraction and quality assessment}

An initial database was developed, pilot tested and refined to ensure consistency with outcomes reported in the literature. Data were extracted from eligible peerreviewed articles by one researcher and verified by a second researcher; data extraction discrepancies were resolved by discussion. The Cochrane Collaboration tool was used for assessing risk of bias in randomised trials. ${ }^{9}$ The risk of bias tool assesses sequence generation, allocation concealment, blinding, incomplete outcome data, selective outcome reporting and other sources of bias. Assessments of the risk of bias were categorised as high, low or uncertain for each item in a given study.

\section{Outcomes}

Tendinopathy pain severity was the efficacy outcome of interest in this analysis. Pain severity on a visual analogue scale (VAS) was preferentially extracted from each study. When not reported, data were extracted from relevant pain severity tools reported in each study. Data from the final follow-up period between 3 and 12 months were used in the main analysis.

\section{Data analysis}

A random effects meta-analysis model was selected a priori for all analyses. The effect size was reported as the 


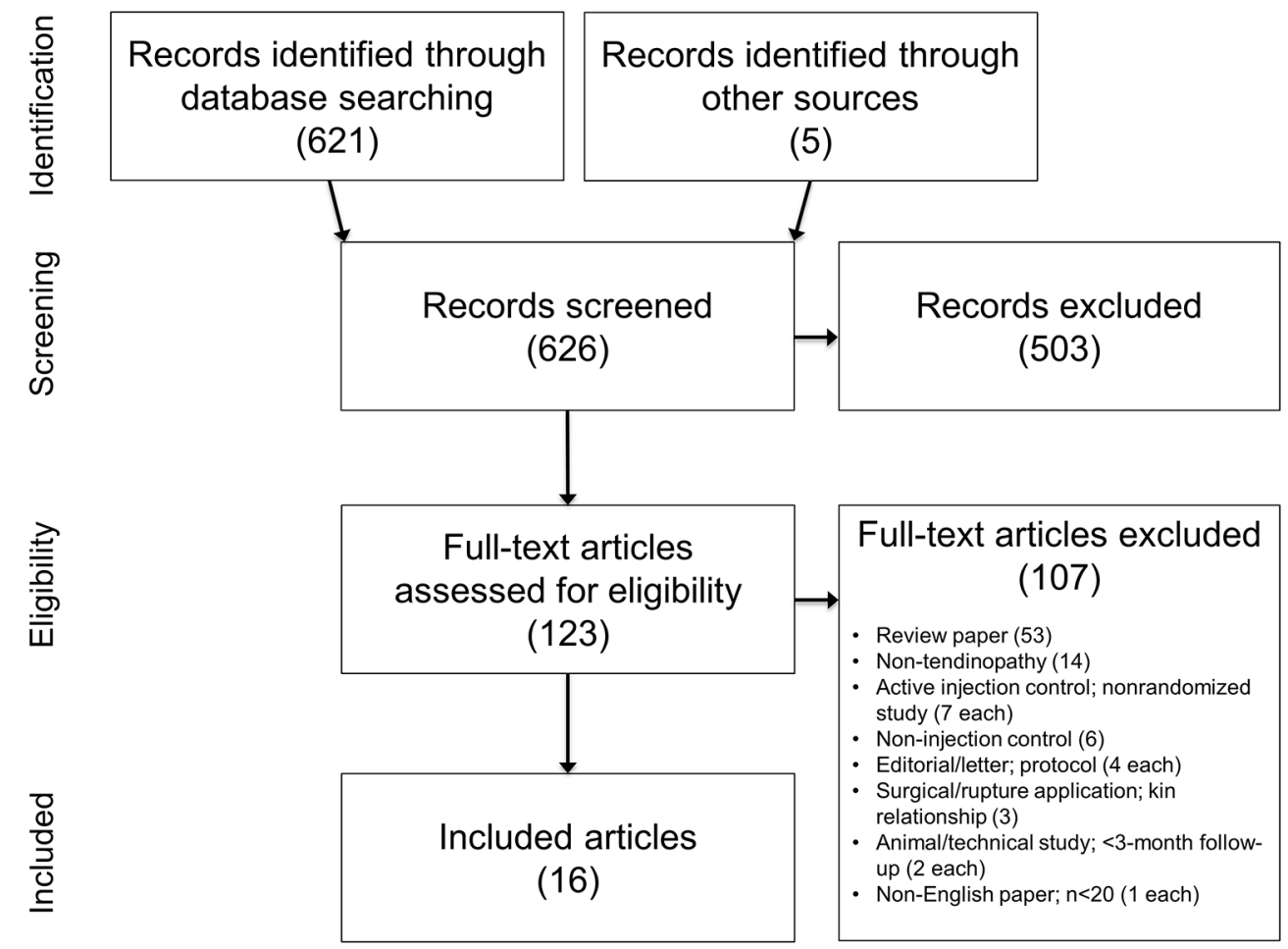

Figure 1 PRISMA (Preferred Reporting Items for Systematic Reviews and Meta-Analyses) flow diagram.

standard mean difference (SMD) for PRP relative to control injection, respectively. For reference, SMD values of $0.2,0.5,0.8$ and 1.0 are defined as small, medium, large and very large effect sizes, respectively. ${ }^{10}$ When a single PRP group was compared with multiple control groups within a study, the sample size of the PRP group entered into the meta-analysis was adjusted based on the number of control groups. ${ }^{11}$ Forest plots were used to visually assess effect sizes and corresponding 95\% CIs across studies. Publication bias was visually assessed with a funnel plot and quantitatively assessed using Egger's regression test. The $\mathrm{I}^{2}$ statistic was used to estimate heterogeneity of treatment effects among studies with values of $\leq 25 \%, 50 \%$ and $\geq 75 \%$ representing low, moderate and high inconsistency, respectively. ${ }^{12}$ Post hoc subgroup analyses and metaregression were undertaken to explore sources of heterogeneity among studies in pain severity. A onestudy removed sensitivity analysis was performed, which recalculates the meta-analysis after removing one study at a time in order to explore the impact of single studies on treatment effects. p Values were two sided with a significance level $<0.05$. All analyses were performed using Comprehensive Meta-analysis (V.2.2, Biostat, Englewood, NJ, USA).

\section{RESULTS}

\section{Study selection}

After screening 626 records for eligibility, 16 randomised controlled trials (18 groups) of PRP versus control injections were included. ${ }^{13-28}$ The most common reasons for exclusion were review paper
(53), non-tendinopathy (14), injection of active control (7; eg, whole blood, PRP) and non-randomised study (7). Several manuscripts were excluded from this review because they were superseded by papers from the same study with longer follow-up including de Vos $e t a l^{29}{ }^{30}$ and Peerbooms $e t a l .{ }^{31} \mathrm{~A}$ flow diagram of study identification and selection is shown in figure 1 .

\section{Patient and study characteristics}

Baseline patient characteristics were comparable between the PRP and control groups (table 1). Overall, $54 \%$ of patients were female and median age was 48 years. Minimum tendinopathy symptom duration ranged from 1 to 6 months (unreported in two studies). Median sample size was 35 patients, a study size that would require an effect size $\geq 1.0$ to achieve statistical significance. Maximum follow-up ranged from 3 to 24 months. The PRP preparation methods and injection protocols used in each study are detailed in table 2. Single injection protocols were used in $81 \%$ of studies. The most common PRP characteristics were $\geq 5 \times$ platelet concentration (10 of 18 groups), increased leucocyte concentration (9 of 17 groups; 1 group unreported) and no PRP activation (16 of 17 groups; 1 group unreported). Controls consisted of saline and/or anaesthetic injection in 11 groups and corticosteroid with or without anaesthetic injection in 7 groups. Risk of bias assessment for each study is detailed in table 3. No study was determined to have low risk of bias, 5 studies had uncertain risk of bias and 11 were at high risk of bias. 
Table 1 Patient and study design characteristics

\begin{tabular}{|c|c|c|c|c|c|c|c|c|c|c|c|}
\hline \multirow[b]{2}{*}{ Study } & \multirow{2}{*}{$\begin{array}{l}\text { Treatment } \\
\text { period }\end{array}$} & \multicolumn{2}{|c|}{ Sample size } & \multicolumn{2}{|c|}{$\begin{array}{l}\text { Female } \\
\text { gender (\%) }\end{array}$} & \multicolumn{2}{|c|}{ Age (year) } & \multirow[b]{2}{*}{ Tendinopathy } & \multirow{2}{*}{$\begin{array}{l}\text { Minimum } \\
\text { symptom } \\
\text { duration } \\
\text { (month) }\end{array}$} & \multirow{2}{*}{$\begin{array}{l}\text { Pain } \\
\text { outcome }\end{array}$} & \multirow{2}{*}{$\begin{array}{l}\text { Follow- } \\
\text { up } \\
\text { (month) }\end{array}$} \\
\hline & & PRP & Control & PRP & Control & PRP & Control & & & & \\
\hline Behera et $a l^{13}$ & 2011-2011 & 15 & 10 & 80 & 50 & 38 & 37 & $\begin{array}{l}\text { Lateral } \\
\text { epicondylar }\end{array}$ & 3 & VAS & 12 \\
\hline Dragoo et $a l^{15}$ & 2009-2012 & A10 & 13 & 11 & 0 & 28 & 40 & Patellar & $1.5^{\star}$ & VAS & 6 \\
\hline Gautam et $a l^{16}$ & 2011-2012 & 15 & 15 & - & - & - & - & $\begin{array}{l}\text { Lateral } \\
\text { epicondylar }\end{array}$ & 6 & VAS & 6 \\
\hline Gosens et al ${ }^{17}$ & 2006-2008 & 51 & 49 & 52 & 56 & 47 & 47 & $\begin{array}{l}\text { Lateral } \\
\text { epicondylar }\end{array}$ & 6 & VAS & $24 \dagger$ \\
\hline Krogh et $a / t_{\ddagger}^{19}$ & 2009-2010 & 20 & 20 & 55 & 55 & 48 & 45 & $\begin{array}{l}\text { Lateral } \\
\text { epicondylar }\end{array}$ & 3 & PRTEE & 3 \\
\hline Krogh et $a / \ddagger_{\ddagger}^{40}$ & 2009-2010 & 20 & 20 & 55 & 45 & 48 & 44 & $\begin{array}{l}\text { Lateral } \\
\text { epicondylar }\end{array}$ & 3 & PRTEE & 3 \\
\hline Krogh et $a l^{20}$ & 2009-2011 & 12 & 12 & 42 & 50 & 47 & 52 & Achilles & 6 & VAS & 3 \\
\hline $\begin{array}{l}\text { Lebiedziński } \\
\text { et } a l^{21}\end{array}$ & 2009-2011 & 64 & 56 & 47 & 74 & 47 & 54 & $\begin{array}{l}\text { Lateral } \\
\text { epicondylar }\end{array}$ & 1.5 & DASH & 12 \\
\hline Mishra et $a l^{22}$ & 2006-2011 & 112 & 113 & - & - & 48 & 47 & $\begin{array}{l}\text { Lateral } \\
\text { epicondylar }\end{array}$ & 3 & VAS & 6 \\
\hline Rha et $a l^{25}$ & 2010-2011 & 20 & 19 & 55 & 58 & 52 & 54 & Rotator cuff & 6 & $\begin{array}{l}\text { SPADI } \\
\text { pain }\end{array}$ & 6 \\
\hline Shams et $a l^{26}$ & 2013-2015 & 20 & 20 & 50 & 45 & 52 & 50 & Rotator cuff & 3 & ASES & 6 \\
\hline $\begin{array}{l}\text { Stenhouse } \\
\text { et }\left.a\right|^{27}\end{array}$ & 2010-2012 & 15 & 13 & 47 & 62 & 53 & 48 & $\begin{array}{l}\text { Lateral } \\
\text { epicondylar }\end{array}$ & 6 & VAS & 6 \\
\hline Yadav et $a l^{28}$ & 2012-2014 & 30 & 30 & 67 & 77 & 37 & 37 & $\begin{array}{l}\text { Lateral } \\
\text { epicondylar }\end{array}$ & 1 & VAS & 3 \\
\hline
\end{tabular}

'-' indicates missing data.

*Patients failed to respond to $\geq 6$ weeks physical therapy; total symptom duration not reported.

$\dagger$ Data extracted through 12 months only for meta-analysis per systematic review methods (ie, data extraction at 3, 6 and 12 months); however, total symptom duration not reported.

$\ddagger$ Study includes same PRP group and different control groups. PRP group sample size adjusted in meta-analysis based on number of groups.

$\S$ Maximum symptom duration was 3 months.

TData extracted through 3 months only for meta-analysis due to implausible reported 6-month outcomes.

ASES, American Shoulder and Elbow Surgeons; DASH, Disabilities of the Arm, Shoulder and Hand score; PRP, platelet-rich plasma; PRTEE, Patient-Rated Tennis Elbow Evaluation; SPADI, Shoulder Pain and Disability Index; VAS, visual analogue scale; VISA-A, Victorian Institute of Sport Assessment-Achilles questionnaire. 
Table 2 Platelet-rich plasma and control injection protocols

\begin{tabular}{|c|c|c|c|c|}
\hline \multirow[b]{2}{*}{ Study } & \multirow[b]{2}{*}{$\begin{array}{l}\text { PRP } \\
\text { type* }\end{array}$} & \multirow{2}{*}{$\begin{array}{l}\text { Number } \\
\text { of } \\
\text { injections }\end{array}$} & \multicolumn{2}{|l|}{ Injection contents and volumet } \\
\hline & & & PRP & Control \\
\hline Behera et $a l^{13}$ & 4B & 1 & $\begin{array}{l}3 \mathrm{~mL} \text { PRP, } 0.5 \mathrm{~mL} \text { calcium } \\
\text { chloride }\end{array}$ & $3 \mathrm{~mL}$ bupivacaine, $0.5 \mathrm{~mL}$ normal saline \\
\hline de Jonge et $a l^{14}$ & $1 \mathrm{~A}$ & 1 & $4 \mathrm{~mL}$ PRP & $4 \mathrm{~mL}$ normal saline \\
\hline Dragoo et $a l^{15}$ & $1 \mathrm{~A}$ & 1 & $3 \mathrm{~mL}$ bupivacaine $\rightarrow 6 \mathrm{~mL}$ PRP & $3 \mathrm{~mL}$ bupivacaine \\
\hline Gautam et al ${ }^{16}$ & 3B & 1 & $2 \mathrm{~mL}$ PRP & $2 \mathrm{~mL}$ methylprednisolone \\
\hline Gosens et al ${ }^{17}$ & $1 \mathrm{~A}$ & 1 & $3 \mathrm{~mL}$ PRP & $3 \mathrm{~mL}$ triamcinolone \\
\hline $\begin{array}{l}\text { Kesikburun } \\
\text { et al }\end{array}$ & $1 \mathrm{~A}$ & 1 & $1 \mathrm{~mL}$ lidocaine $\rightarrow 5 \mathrm{~mL}$ PRP & $1 \mathrm{~mL}$ lidocaine $\rightarrow 5 \mathrm{~mL}$ normal saline \\
\hline Krogh et al ${ }^{19}$ & $1 \mathrm{~A}$ & 1 & $\begin{array}{l}10-15 \mathrm{~mL} \text { lidocaine } \rightarrow 3 \mathrm{~mL} \\
\text { PRP }\end{array}$ & $10-15 \mathrm{~mL}$ lidocaine $\rightarrow 3 \mathrm{~mL}$ normal saline \\
\hline Krogh et $a l^{40}$ & $1 \mathrm{~A}$ & 1 & $\begin{array}{l}\text { 10-15 mL lidocaine } \rightarrow 3 \mathrm{~mL} \\
\text { PRP }\end{array}$ & $\begin{array}{l}10-15 \mathrm{~mL} \text { lidocaine } \rightarrow 1 \mathrm{~mL} \text { triamcinolone, } 2 \mathrm{~mL} \\
\text { lidocaine }\end{array}$ \\
\hline Krogh et $a l^{20}$ & $1 \mathrm{~A}$ & 1 & $\begin{array}{l}10-15 \mathrm{~mL} \text { lidocaine } \rightarrow 6 \mathrm{~mL} \\
\text { PRP }\end{array}$ & $10-15 \mathrm{~mL}$ lidocaine $\rightarrow 6 \mathrm{~mL}$ normal saline \\
\hline $\begin{array}{l}\text { Lebiedziński } \\
\text { et } a l^{21}\end{array}$ & 3B & 1 & $3 \mathrm{~mL}$ PRP & $1 \mathrm{~mL}$ betamethasone, $2 \mathrm{~mL}$ lignocaine \\
\hline Mishra et $a l^{22}$ & $1 \mathrm{~A}$ & 1 & Bupivacaine $\ddagger \rightarrow 2-3 \mathrm{~mL}$ PRP & Bupivacaine $\ddagger \rightarrow 2-3 \mathrm{~mL}$ bupivacaine \\
\hline $\begin{array}{l}\text { Montalvan } \\
\text { et } a l^{23}\end{array}$ & 3B & $2 \S$ & $2 \mathrm{~mL}$ lidocaine $\rightarrow 2 \mathrm{~mL}$ PRP & $2 \mathrm{~mL}$ lidocaine $\rightarrow 2 \mathrm{~mL}$ normal saline \\
\hline Palacio et $\mathrm{al}^{24}$ & 3B & 1 & $3 \mathrm{~mL}$ PRP & $3 \mathrm{~mL}$ neocaine \\
\hline Palacio et $\mathrm{al}^{24}$ & 3B & 1 & $3 \mathrm{~mL}$ PRP & $3 \mathrm{~mL}$ dexamethasone \\
\hline Rha et $a l^{25}$ & $1 \mathrm{~A}$ & $2 \S$ & $<1 \mathrm{~mL}$ lidocaine $\rightarrow 3 \mathrm{~mL}$ PRP & $<1 \mathrm{~mL}$ lidocaine \\
\hline Shams et $a l^{26}$ & 3B & 1 & 2-2.5 mL PRP & $5 \mathrm{~mL}$ triamcinolone \\
\hline $\begin{array}{l}\text { Stenhouse } \\
\text { et } a l^{27}\end{array}$ & 3B & $2 \S$ & $\begin{array}{l}1-2 \mathrm{~mL} \text { lignocaine } \rightarrow 2 \mathrm{~mL} \\
\text { PRP }\end{array}$ & 1-2 mL lignocaine \\
\hline Yadav et $\left.a\right|^{28}$ & $\# A \rrbracket$ & 1 & $1 \mathrm{~mL}$ PRP & $1 \mathrm{~mL}$ methylprednisolone \\
\hline
\end{tabular}

*From Mishra et $a l^{41}$ ( $1 \mathrm{~A}=$ high platelet concentration with leucocyte counts $>$ whole blood and no exogenous platelet activation, $3 \mathrm{~B}=$ low platelet concentration with leucocyte counts $<$ whole blood and no exogenous platelet activation, $4 \mathrm{~B}=3 \mathrm{~B}$ but with exogenous platelet activation).

$\dagger^{\prime} \rightarrow$ ' implies sequential injection.

$\ddagger$ Volume unspecified.

§Injections separated by 4-week interval.

ILeucocyte concentration and activation method unknown.

PRP, platelet-rich plasma.

\section{PRP efficacy}

Injection of PRP resulted in statistically lower pain severity relative to control in 8 of 18 groups, 10 of 18 groups reported no differences, and no groups reported greater efficacy with control over PRP. In the random effects meta-analysis, PRP was associated with lower tendinopathy pain severity. The SMD for PRP was 0.47 (95\% CI 0.22 to $0.72, p<0.001)$, which is considered a moderate treatment effect (figure 2). No evidence of publication bias (Egger's regression $p=0.66$; figure 3 ) was found. Heterogeneity among studies was moderate $\left(\mathrm{I}^{2}=67 \%, \mathrm{p}<0.001\right)$. Potential sources of heterogeneity in treatment effects were investigated with subgroup analyses (table 4). The only variable that was shown to influence PRP efficacy was female sex. In the eight groups with proportion of women above the overall median, a large treatment effect was observed $(\mathrm{SMD}=0.71)$. However, in the remaining six groups with fewer women, the treatment benefit was negligible $(\mathrm{SMD}=0.11)$. The relationship between female sex and PRP efficacy was further confirmed in meta-regression where the proportion of women in each study explained $34 \%$ of the variability in treatment effects $(p<0.001)$ (figure 4). In the subgroup analysis, other variables that 
Table 3 Cochrane risk of bias assessment

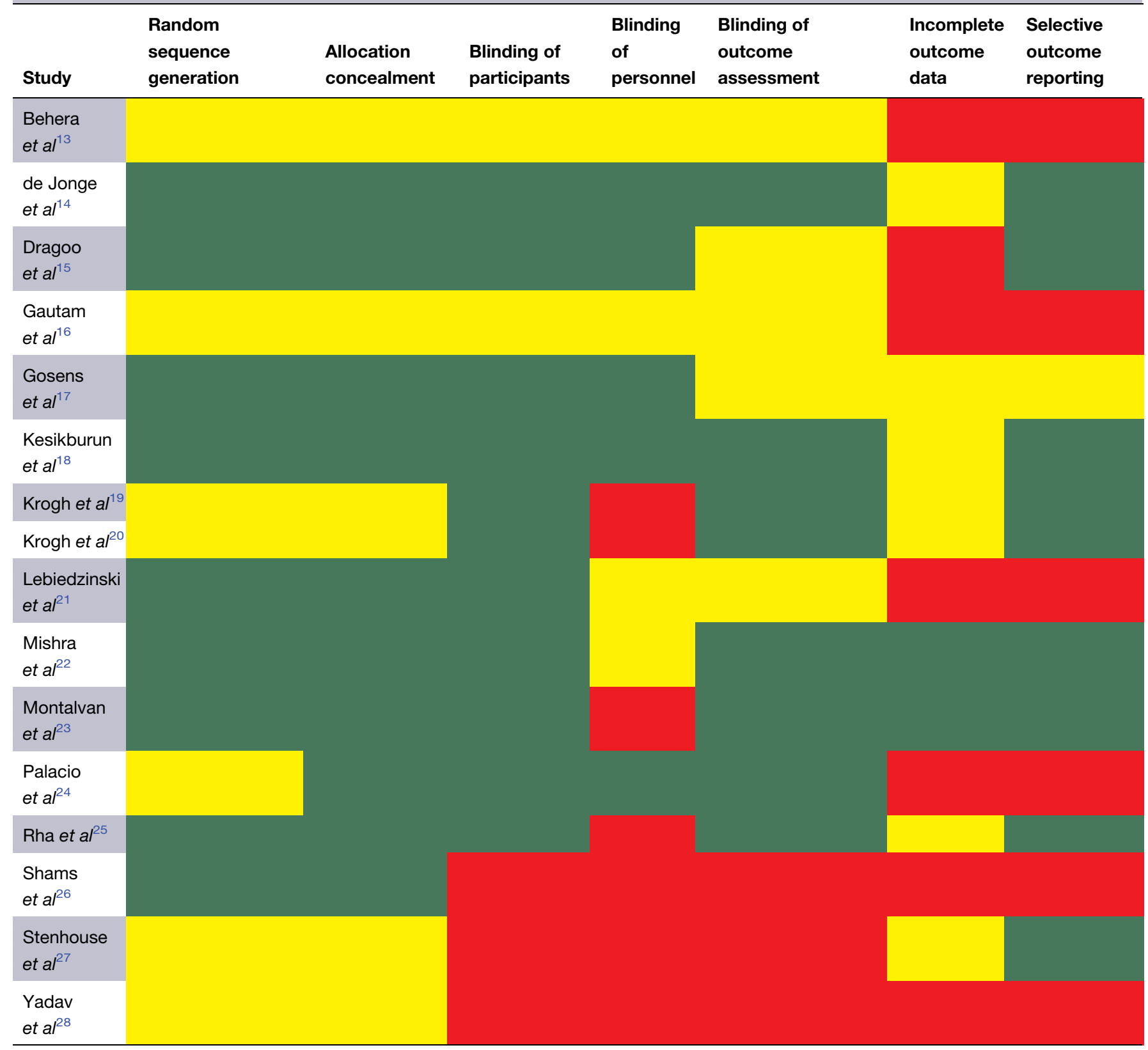

Green colour indicates low bias risk; yellow colour indicates uncertain bias risk and red colour indicates high bias risk.

were associated with clinically meaningful differences in PRP efficacy (SMD $\geq 0.3$ ), yet did not achieve statistical significance, were tendinopathy location (lateral epicondylar over other locations) and maximum follow-up duration (12 months over 3 months). Thus, while these comparisons were underpowered, the results suggest that PRP may have greater efficacy in lateral epicondylar tendinopathy or with longer follow-up duration. The 'one study removed' sensitivity analysis demonstrated that no single study significantly altered conclusions of the main analyses when removed from the analysis, with the SMD in all scenarios ranging from 0.39 to 0.51 (all $\mathrm{p} \leq 0.001$ ) (figure 5).

\section{DISCUSSION}

The results of this systematic review and meta-analysis provide level 1 evidence that injection of PRP is efficacious in patients with symptomatic tendinopathy. The treatment effects with PRP relative to controls in this meta-analysis suggest clinically meaningful improvements in patient symptoms.

Previous meta-analyses have drawn disparate conclusions regarding PRP efficacy, likely because of widely varying methodologies among studies. ${ }^{32-38}$ We designed the current review to minimise potential sources of bias, namely by excluding non-randomised studies, studies with non-injection control groups, or 


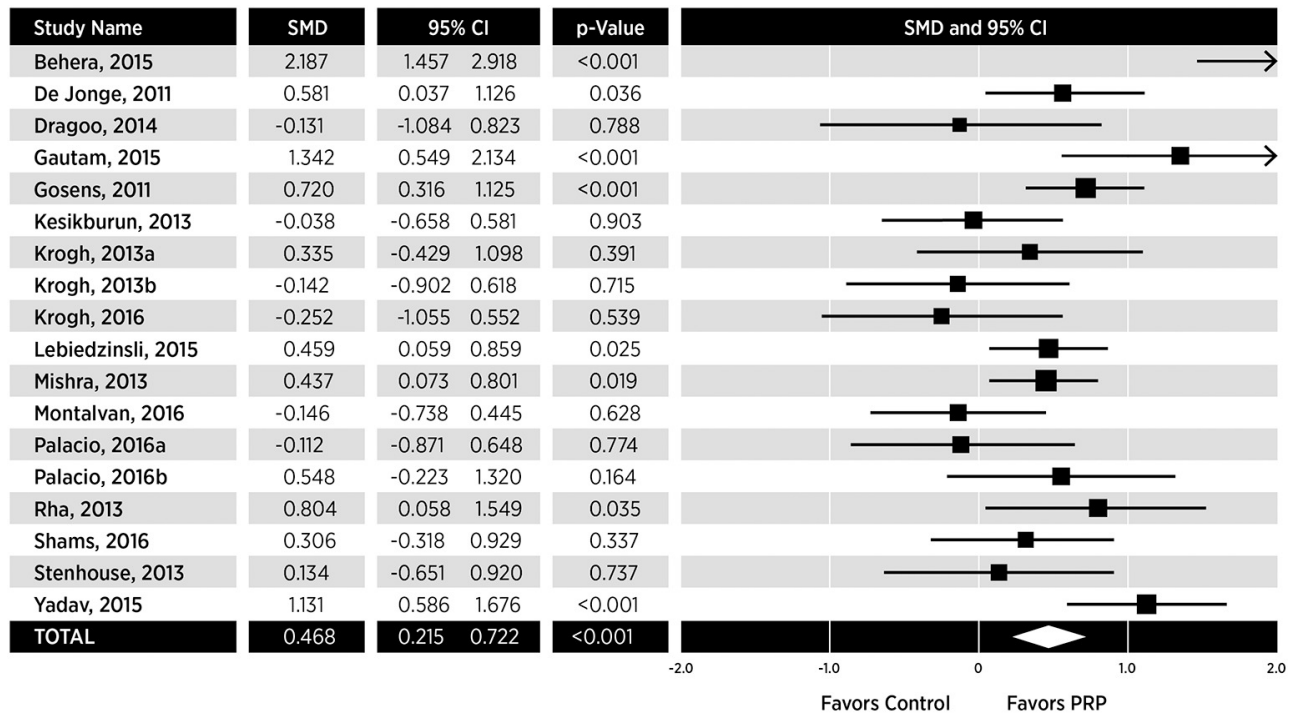

Figure 2 Forest plot of platelet-rich plasma (PRP) versus control on tendinopathy pain. Random effects meta-analysis using the standard mean difference statistic for PRP versus control. A pooled estimate of overall standard mean difference (diamond) and $95 \% \mathrm{Cl}$ (diamond width) summarises the effect size. Standard mean difference values of $0.2,0.5,0.8$ and 1.0 are defined as small, medium, large and very large effect sizes, respectively. Effects to the left of 0 indicate greater efficacy with control; effects to the right of 0 indicate greater efficacy with PRP. When the horizontal bars of an individual study, or the pooled diamond width, cross 0 , the effect is not significantly different. Heterogeneity: $l^{2}=67 \%, p<0.001$. SMD, standard mean difference.

active injectable controls (eg, whole blood, PRP). Still, we identified significant heterogeneity in treatment effects. When evaluating patient, treatment and study design-related factors, female sex was the only variable that modified the efficacy of PRP for treatment of tendinopathy. The observation that PRP may be more efficacious in women has been previously reported. Wesner et $a l^{39}$ reported that the magnitude of pain reduction on a $0-10$ scale was greater in women than men $(2.8$ vs $1.8, \mathrm{p}=0.04)$ with PRP injection in degenerative tendinopathy. While no obvious explanation exists for this post hoc observation, exploration of gender differences with PRP injection should be explored in future studies.
Lateral epicondylar tendinopathy was evaluated in most comparisons (12 of 18 groups) and was the most responsive to PRP therapy (effect size $=0.57$ ). For comparison, rotator cuff (three groups; effect size $=0.32$ ), Achilles (two groups; effect size $=0.22$ ) and patellar tendon (one group; effect size $=-0.13$ ) pathology were less studied and had negligible to small effect sizes. In agreement with our findings, others have reported that PRP is particularly efficacious for lateral epicondylar tendinopathy. ${ }^{37}{ }^{40}$ While this meta-analysis was underpowered to detect meaningful differences in treatment effects among anatomical sites, it is plausible that PRP efficacy may also be influenced by injection site.

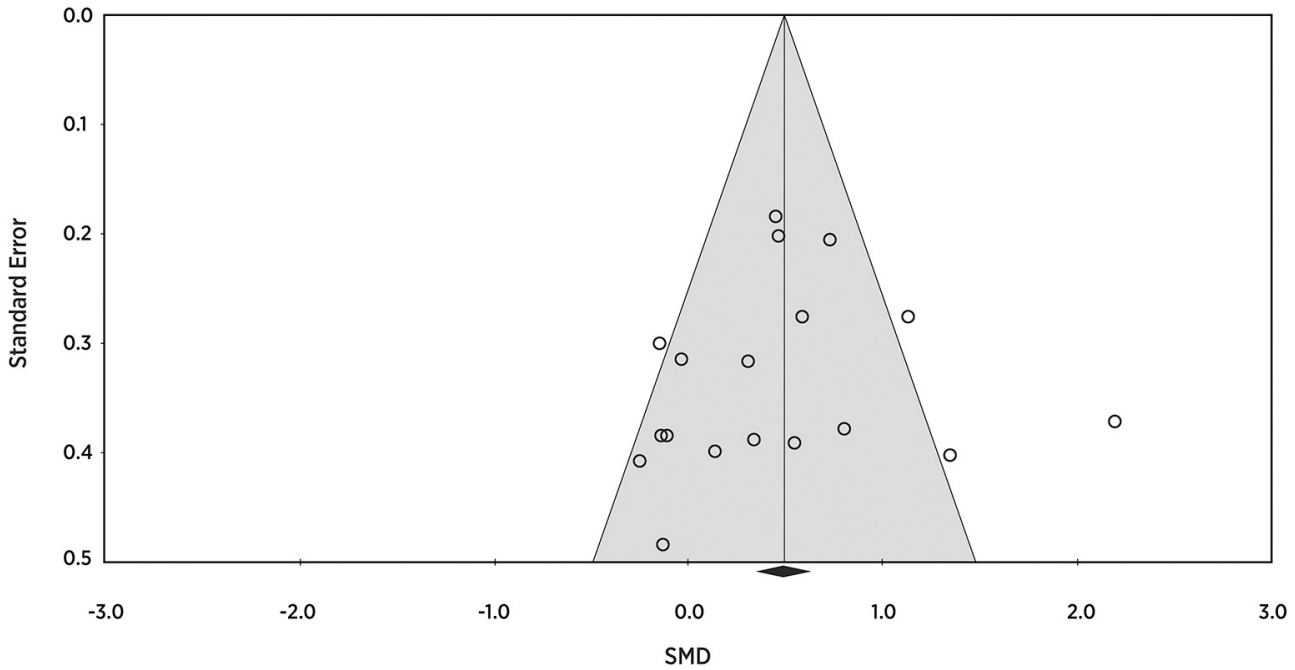

Figure 3 Funnel plot of standard mean difference in platelet-rich plasma efficacy across studies. Egger's $p$ value $=0.66$ for publication bias. SMD, standard mean difference. 
Table 4 Subgroup analysis of patient and study-related factors on tendinopathy pain improvement with PRP versus control injection

\begin{tabular}{|c|c|c|c|}
\hline Comparison & $\begin{array}{l}\text { Number of } \\
\text { studies }\end{array}$ & SMD & $\begin{array}{l}\mathbf{p} \\
\text { Value* }\end{array}$ \\
\hline \multicolumn{4}{|l|}{ Female proportion $\dagger$} \\
\hline$\geq 54 \%$ & 8 & 0.71 & 0.02 \\
\hline$<54 \%$ & 6 & 0.11 & \\
\hline \multicolumn{4}{|l|}{ Tendinopathy location } \\
\hline Lateral epicondylar & 12 & 0.57 & 0.18 \\
\hline Other & 6 & 0.26 & \\
\hline \multicolumn{4}{|l|}{ Corticosteroid control } \\
\hline Yes & 7 & 0.63 & 0.27 \\
\hline No & 11 & 0.36 & \\
\hline \multicolumn{4}{|l|}{ No. of injections } \\
\hline One & 15 & 0.51 & 0.39 \\
\hline Two & 3 & 0.23 & \\
\hline \multicolumn{4}{|l|}{$\begin{array}{l}\text { PRP leucocyte } \\
\text { concentration }\end{array}$} \\
\hline Increased (type 1 or 2$) \ddagger$ & 9 & 0.35 & 0.43 \\
\hline $\begin{array}{l}\text { Minimal or none (type } 3 \\
\text { or } 4) \ddagger\end{array}$ & 8 & 0.58 & \\
\hline \multicolumn{4}{|l|}{ Patient age $\dagger$} \\
\hline$<48$ years & 7 & 0.59 & 0.44 \\
\hline$\geq 48$ years & 7 & 0.34 & \\
\hline \multicolumn{4}{|l|}{ Pain assessment tool } \\
\hline VAS & 10 & 0.55 & 0.51 \\
\hline Other & 8 & 0.39 & \\
\hline
\end{tabular}

PRP platelet

concentration

\begin{tabular}{|c|c|c|c|}
\hline$\geq 5 \times($ type A) $\ddagger$ & 10 & 0.42 & 0.59 \\
\hline$<5 \times($ type $B) \ddagger$ & 8 & 0.58 & \\
\hline \multicolumn{4}{|c|}{ Maximum follow-up } \\
\hline 12 months & 6 & 0.60 & 0.67 \\
\hline 6 months & 6 & 0.49 & \\
\hline 3 months & 6 & 0.29 & \\
\hline \multicolumn{4}{|c|}{ Total sample size $\dagger$} \\
\hline$\geq 35$ patients & 9 & 0.48 & 0.90 \\
\hline$<35$ patients & 9 & 0.45 & \\
\hline
\end{tabular}

Minimum symptom

duration

\begin{tabular}{cccc}
6 months & 5 & 0.57 & 0.91 \\
3 months & 6 & 0.51 & \\
$<3$ months & 5 & 0.43 & \\
\hline
\end{tabular}

Continued
Table 4 Continued

\begin{tabular}{lccl}
\hline Comparison & $\begin{array}{l}\text { Number of } \\
\text { studies }\end{array}$ & SMD & $\begin{array}{l}\mathbf{p} \\
\text { Value* }\end{array}$ \\
\hline Risk of bias & & & \\
Uncertain & 4 & 0.47 & $>0.99$ \\
High & 14 & 0.47 & \\
\hline
\end{tabular}

* $\mathrm{p}$ Value for subgroup comparisons.

$\dagger$ Values for comparisons represent the median for all studies.

tFrom Mishra et al..$^{41}$

PRP, platelet—rich plasma; SMD, standard mean difference; VAS, visual analogue scale.

Two randomised controlled trials that were included in this meta-analysis warrant additional discussion. First, in the study of Behera and colleagues,${ }^{13}$ the treatment benefit of PRP relative to control was considerably greater than any other included study (effect size=2.2). Over 1-year follow-up, pain scores on a $0-100$ scale decreased from $75 \pm 6$ to $13 \pm 14$ with PRP and from $76 \pm 7$ to $41 \pm 12$ with control (bupivacaine) injection. While exclusion of this study in a one-study removed analysis did not change the conclusions of this meta-analysis, heterogeneity in outcomes among the remaining studies was non-existent following removal of this study. Although no specific attributes of this study that may dramatically impact outcomes are readily observable, the inclusion of this study does introduce considerable inconsistency to our findings. Second, the study by Dragoo and colleagues ${ }^{15}$ reported an unprecedented and profound recovery in the bupivacaine control group at the final time point. For example, VAS pain scores in the control group were $3.0 \pm 2.3$ at baseline, $2.3 \pm 1.6$ at 12 weeks and $0.3 \pm 0.5$ at 26 weeks. This $90 \%$ reduction in mean pain severity with control over a 6-month time frame was notably greater than in any other study of control injections. Complete recovery of a non-active control group in a randomised controlled trial for an orthopaedics indication is unanticipated. As before, exclusion of this study in a one-study removed analysis did not change the conclusions of this meta-analysis and no specific attributes of this study that may dramatically impact outcomes are readily observable.

The sample sizes of most PRP studies for symptomatic tendinopathy were too small to statistically detect clinically meaningful treatment effects. To detect the effect size of PRP observed in this meta-analysis, a sample size of 146 patients ( 73 per group) would be required. In this review, only 1 of 18 groups enrolled at least this number of patients. In fact, the median sample size in this review was only 35 patients. This observation likely explains why many individual studies showed no benefit of PRP, yet the results of the pooled analysis showed a statistically significant, moderate benefit relative to control injections. 


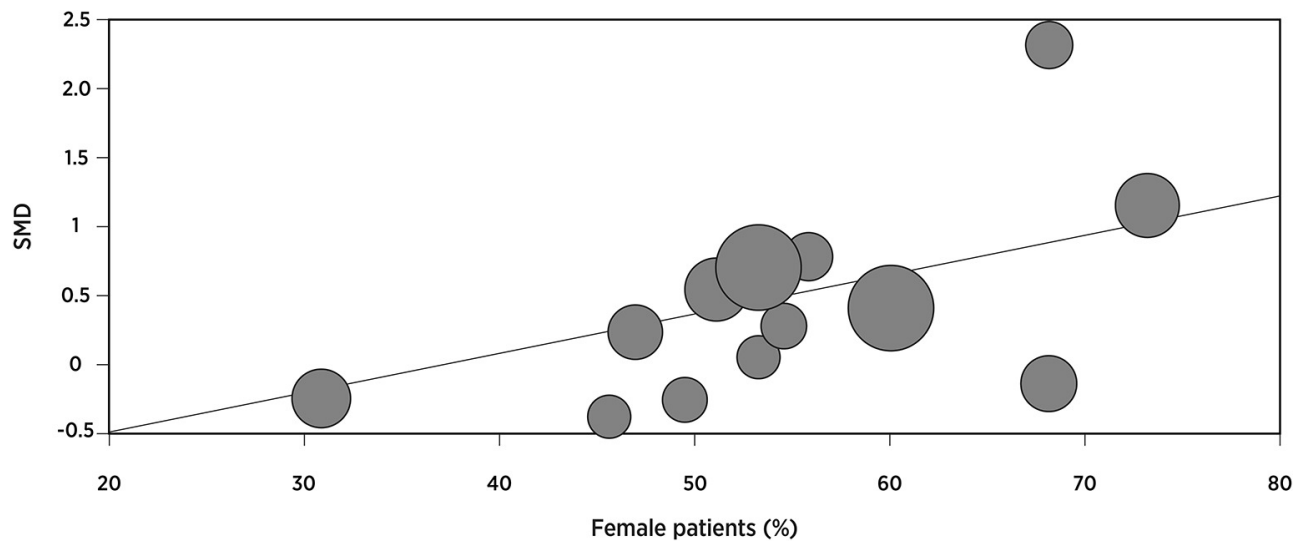

Figure 4 Meta-regression of relationship between proportion of women in each study and platelet-rich plasma efficacy. Percentage of explained variance $=34 \%, p<0.001$. Markers are proportional to sample size. SMD, standard mean difference.

A similar observation can be made about the systematic review by de Vos $e t a l^{36}$ who concluded that there was strong evidence against PRP for chronic lateral epicondylar tendinopathy. This conclusion was based on the observation that only one of six included studies showed a positive benefit of PRP, yet no attempt was made at quantitative data synthesis. (What was the effect size and direction of the analysis when you reviewed it?) These results underscore the need for investigators to perform power analyses with realistic assumptions during study planning and for systematic reviewers to consider meta-analytic techniques, where appropriate, to quantify treatment effects with more precision than simple counts of positive studies.

Our meta-analysis is associated with several issues that may influence interpretation. Strengths of this meta-analysis are inclusion of only randomised, injection-controlled trials, structured data extraction methodology and comprehensive analysis of potentially confounding factors. There were also limitations inherent in the studies that were included in this review. First, the duration of tendinopathy symptoms was variable, frequently of short duration, and, in many cases, inadequately described. Thus, this meta-analysis was unable to discern the efficacy of PRP based on chronology of symptoms. Second, there was significant heterogeneity in efficacy outcomes among studies with PRP versus control injections. While subgroup and meta-regression identified female sex as a potential mediating factor, definitive conclusions cannot be drawn given the post hoc nature of the analysis. Third, the duration of patient follow-up may be an important

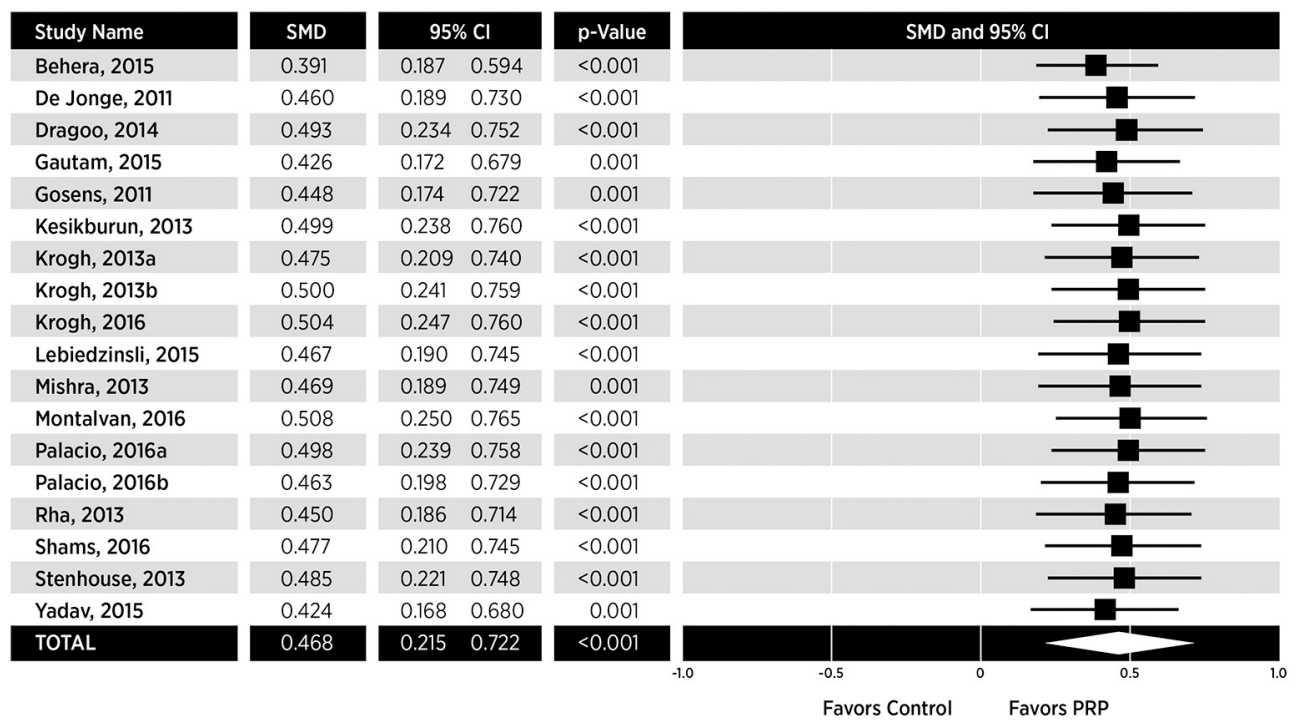

Figure 5 Forest plot for one-study removed sensitivity analysis of platelet-rich plasma (PRP) versus control on tendinopathy pain. Random effects meta-analysis using the standard mean difference statistic for PRP versus control. A pooled estimate of overall standard mean difference (diamond) and $95 \% \mathrm{Cl}$ (diamond width) summarises the effect size. Standard mean difference values of $0.2,0.5,0.8$ and 1.0 are defined as small, medium, large and very large effect sizes, respectively. Effects to the left of 0 indicate greater efficacy with control; effects to the right of 0 indicate greater efficacy with PRP. When the horizontal bars of an individual study, or the pooled diamond width, cross 0 , the effect is not significantly different. SMD, standard mean difference. 
determinant of PRP efficacy. Subgroup analyses demonstrated greater effect sizes with PRP with greater follow-up duration. Although the analysis was underpowered to detect important differences given the limited number of studies with varying follow-up durations, the magnitude of the effect size with PRP at 12 months and the effect size difference from 3 to 12 months suggests that PRP efficacy may continue to improve through at least 12 months follow-up. Thus, researchers are encouraged to enrol an adequate number of patients and continue follow-up through at least 1 year post-treatment. Third, we made no attempt to assess safety of PRP injections in this study. Generally, safety reporting in the PRP literature is inconsistent and inadequate. While treatment-related complications with PRP such as pain and swelling are generally infrequent, mild and transient, the potential for unreported complications remains a major limitation of the PRP literature in general and the consequent absence of pooled safety data is a limitation of this meta-analysis.

\section{CONCLUSIONS}

Injection of PRP is more efficacious than control injections in patients with symptomatic tendinopathy. Indications for use and PRP preparation methods should continue to be refined in an effort to reduce variability in outcomes and identify optimal treatment conditions.

Acknowledgements We thank David Fay, PhD, for assistance with literature review.

Contributors Conception and design: LEM, WRP, BR, SB. Analysis of the data: LEM. Interpretation of the data: LEM, WRP, BR, SB. Drafting of the article: LEM. Critical revision of the article for important intellectual content: LEM, WRP, BR, SB. Final approval of the article: LEM, WRP, BR, SB.

Funding We disclose that financial support for this work was provided by DePuy Synthes Mitek Sports Medicine (Raynham, MA).

Competing interests None declared.

Provenance and peer review Not commissioned; externally peer reviewed.

Data sharing statement No additional data are available.

Open Access This is an Open Access article distributed in accordance with the Creative Commons Attribution Non Commercial (CC BY-NC 4.0) license, which permits others to distribute, remix, adapt, build upon this work noncommercially, and license their derivative works on different terms, provided the original work is properly cited and the use is non-commercial. See: http:// creativecommons.org/licenses/by-nc/4.0/

(C) Article author(s) (or their employer(s) unless otherwise stated in the text of the article) 2017. All rights reserved. No commercial use is permitted unless otherwise expressly granted.

\section{REFERENCES}

1. Forde MS, Punnett L, Wegman DH. Prevalence of musculoskeletal disorders in union ironworkers. J Occup Environ Hyg 2005;2:203-12.

2. Benjamin M, Ralphs JR. Tendons and ligaments-an overview. Histol Histopathol 1997;12:1135-44.

3. Khan KM, Cook JL, Kannus P, et al. Time to abandon the "tendinitis" myth. BMJ 2002;324:626-7.
4. Martínez CE, Smith PC, Palma Alvarado VA. The influence of platelet-derived products on angiogenesis and tissue repair: a concise update. Front Physiol 2015;6:290.

5. Anitua E, Sánchez M, Orive G. Potential of endogenous regenerative technology for in situ regenerative medicine. Adv Drug Deliv Rev 2010;62(7-8):741-52.

6. Molloy T, Wang Y, Murrell G. The roles of growth factors in tendon and ligament healing. Sports Med 2003;33:381-94.

7. Foster TE, Puskas BL, Mandelbaum BR, et al. Platelet-rich plasma: from basic science to clinical applications. Am J Sports Med 2009;37:2259-72.

8. Liberati A, Altman DG, Tetzlaff J, et al. The PRISMA statement for reporting systematic reviews and meta-analyses of studies that evaluate health care interventions: explanation and elaboration. Ann Intern Med 2009;151:W-94

9. Higgins JP, Altman DG, Gøtzsche PC, et al. The Cochrane Collaboration's tool for assessing risk of bias in randomised trials. BMJ 2011;343:d5928.

10. Cohen J. Statistical power analysis for the behavioral sciences. Hillside, NJ: Lawrence Erlbaum Associates, 1987.

11. Higgins JPT, Green S. Cochrane Handbook for Systematic Reviews of Interventions Version 5.1.0 [updated March 2011]. ed: The Cochrane Collaboration. 2011. www.cochrane-handbook.org.

12. Higgins JP, Thompson SG, Deeks JJ, et al. Measuring inconsistency in meta-analyses. BMJ 2003;327:557-60.

13. Behera $\mathrm{P}$, Dhillon M, Aggarwal S, et al. Leukocyte-poor platelet-rich plasma versus bupivacaine for recalcitrant lateral epicondylar tendinopathy. J Orthop Surg 2015;23:6-10.

14. de Jonge S, de Vos RJ, Weir A, et al. One-year follow-up of plateletrich plasma treatment in chronic Achilles tendinopathy: a doubleblind randomized placebo-controlled trial. Am J Sports Med 2011;39:1623-9.

15. Dragoo JL, Wasterlain AS, Braun $\mathrm{HJ}$, et al. Platelet-rich plasma as a treatment for patellar tendinopathy: a double-blind, randomized controlled trial. Am J Sports Med 2014;42:610-8.

16. Gautam VK, Verma S, Batra S, et al. Platelet-rich plasma versus corticosteroid injection for recalcitrant lateral epicondylitis: clinical and ultrasonographic evaluation. J Orthop Surg 2015;23:1-5.

17. Gosens T, Peerbooms JC, van Laar W, et al. Ongoing positive effect of platelet-rich plasma versus corticosteroid injection in lateral epicondylitis: a double-blind randomized controlled trial with 2-year follow-up. Am J Sports Med 2011;39:1200-8.

18. Kesikburun S, Tan AK, Yilmaz B, et al. Platelet-rich plasma injections in the treatment of chronic rotator cuff tendinopathy: a randomized controlled trial with 1-year follow-up. Am J Sports Med 2013;41:2609-16.

19. Krogh TP, Fredberg U, Stengaard-Pedersen K, et al. Treatment of lateral epicondylitis with platelet-rich plasma, glucocorticoid, or saline: a randomized, double-blind, placebo-controlled trial. Am J Sports Med 2013;41:625-35.

20. Krogh TP, Ellingsen T, Christensen R, et al. Ultrasound-Guided Injection Therapy of Achilles Tendinopathy With Platelet-Rich Plasma or Saline: A Randomized, Blinded, Placebo-Controlled Trial. Am J Sports Med 2016;44:1990-7.

21. Lebiedziński $R$, Synder $M$, Buchcic $P$, et al. A randomized study of autologous conditioned plasma and steroid injections in the treatment of lateral epicondylitis. Int Orthop 2015;39:2199-203.

22. Mishra AK, Skrepnik NV, Edwards SG, et al. Efficacy of platelet-rich plasma for chronic tennis elbow: a double-blind, prospective, multicenter, randomized controlled trial of 230 patients. Am J Sports Med 2014;42:463-71.

23. Montalvan B, Le Goux P, Klouche S, et al. Inefficacy of ultrasoundguided local injections of autologous conditioned plasma for recent epicondylitis: results of a double-blind placebo-controlled randomized clinical trial with one-year follow-up. Rheumatology 2016;55:279-85.

24. Palacio EP, Schiavetti RR, Kanematsu M, et al. Effects of plateletrich plasma on lateral epicondylitis of the elbow: prospective randomized controlled trial. Rev Bras Ortop 2016;51:90-5.

25. Rha DW, Park GY, Kim YK, et al. Comparison of the therapeutic effects of ultrasound-guided platelet-rich plasma injection and dry needling in rotator cuff disease: a randomized controlled trial. Clin Rehabil 2013:27:113-22.

26. Shams A, El-Sayed M, Gamal O, et al. Subacromial injection of autologous platelet-rich plasma versus corticosteroid for the treatment of symptomatic partial rotator cuff tears. Eur J Orthop Surg Traumatol 2016;26:837-42.

27. Stenhouse G, Sookur P, Watson M. Do blood growth factors offer additional benefit in refractory lateral epicondylitis? A prospective, randomized pilot trial of dry needling as a stand-alone procedure 
versus dry needling and autologous conditioned plasma. Skeletal Radiol 2013;42:1515-20.

28. Yadav R, Kothari SY, Borah D. Comparison of Local Injection of Platelet Rich Plasma and Corticosteroids in the Treatment of Lateral Epicondylitis of Humerus. J Clin Diagn Res 2015;9:RC05-7.

29. de Vos RJ, Weir A, van Schie HT, et al. Platelet-rich plasma injection for chronic Achilles tendinopathy: a randomized controlled trial. JAMA 2010;303:144-9.

30. de Vos RJ, Weir A, Tol JL, et al. No effects of PRP on ultrasonographic tendon structure and neovascularisation in chronic midportion Achilles tendinopathy. Br J Sports Med 2011;45:387-92.

31. Peerbooms JC, Sluimer J, Bruijn DJ, et al. Positive effect of an autologous platelet concentrate in lateral epicondylitis in a doubleblind randomized controlled trial: platelet-rich plasma versus corticosteroid injection with a 1-year follow-up. Am J Sports Med 2010;38:255-62.

32. Balasubramaniam U, Dissanayake R, Annabell L. Efficacy of plateletrich plasma injections in pain associated with chronic tendinopathy: A systematic review. Phys Sportsmed 2015;43:253-61.

33. Liddle $A D$, Rodríguez-Merchán EC. Platelet-Rich Plasma in the Treatment of Patellar Tendinopathy: A Systematic Review. Am J Sports Med 2015;43:2583-90.

34. Di Matteo B, Filardo G, Kon E, et al. Platelet-rich plasma: evidence for the treatment of patellar and Achilles tendinopathy-a systematic review. Musculoskelet Surg 2015;99:1-9.
35. Andia I, Latorre PM, Gomez MC, et al. Platelet-rich plasma in the conservative treatment of painful tendinopathy: a systematic review and meta-analysis of controlled studies. Br Med Bull 2014;110:99-115.

36. de Vos RJ, Windt J, Weir A. Strong evidence against platelet-rich plasma injections for chronic lateral epicondylar tendinopathy: a systematic review. Br J Sports Med 2014:48:952-6.

37. Arirachakaran A, Sukthuayat A, Sisayanarane T, et al. Platelet-rich plasma versus autologous blood versus steroid injection in lateral epicondylitis: systematic review and network meta-analysis. $J$ Orthop Traumatol 2016;17:101-12.

38. Rabago D, Best TM, Zgierska AE, et al. A systematic review of four injection therapies for lateral epicondylosis: prolotherapy, polidocanol, whole blood and platelet-rich plasma. Br J Sports Med 2009;43:471-81.

39. Wesner M, Defreitas T, Bredy $\mathrm{H}$, et al. A Pilot Study Evaluating the Effectiveness of Platelet-Rich Plasma Therapy for Treating Degenerative Tendinopathies: A Randomized Control Trial with Synchronous Observational Cohort. PLoS One 2016;11:e0147842.

40. Krogh TP, Bartels EM, Ellingsen T, et al. Comparative effectiveness of injection therapies in lateral epicondylitis: a systematic review and network meta-analysis of randomized controlled trials. Am J Sports Med 2013;41:1435-46.

41. Mishra A, Harmon K, Woodall J, et al. Sports medicine applications of platelet rich plasma. Curr Pharm Biotechnol 2012;13:1185-95. 